\title{
ERRATUM
}

\section{Integrated bioprocess for the production and purification of recombinant proteins by affinity chromatography in Escherichia coli}

\author{
Usama Beshay · Gerhard Miksch · Karl Friehs · \\ Erwin Flaschel
}

Published online: 6 November 2008

(c) Springer-Verlag 2008

\section{Erratum to: Bioprocess Biosyst Eng}

\section{DOI 10.1007/s00449-008-0227-3}

The original version of this article unfortunately contained a mistake.
The online version of the original article can be found under doi: 10.1007/s00449-008-0227-3.

\section{U. Beshay $(\square)$}

Bioprocess Development Department,

Mubarak City for Scientific Research and Technology

Applications, Genetic Engineering and Biotechnology Research Institute (GEBRI), New Borg El-Arab, Alexandria 21934, Egypt e-mail: ube@fermtech.techfak.uni-bielefeld.de

G. Miksch - K. Friehs - E. Flaschel

Technische Fakultaet, Universitaet Bielefeld,

AG Fermentationstechnik, 33594 Bielefeld, Germany
Figures 6 and 7 were identical.

The correct version of Fig. 6 is given below.
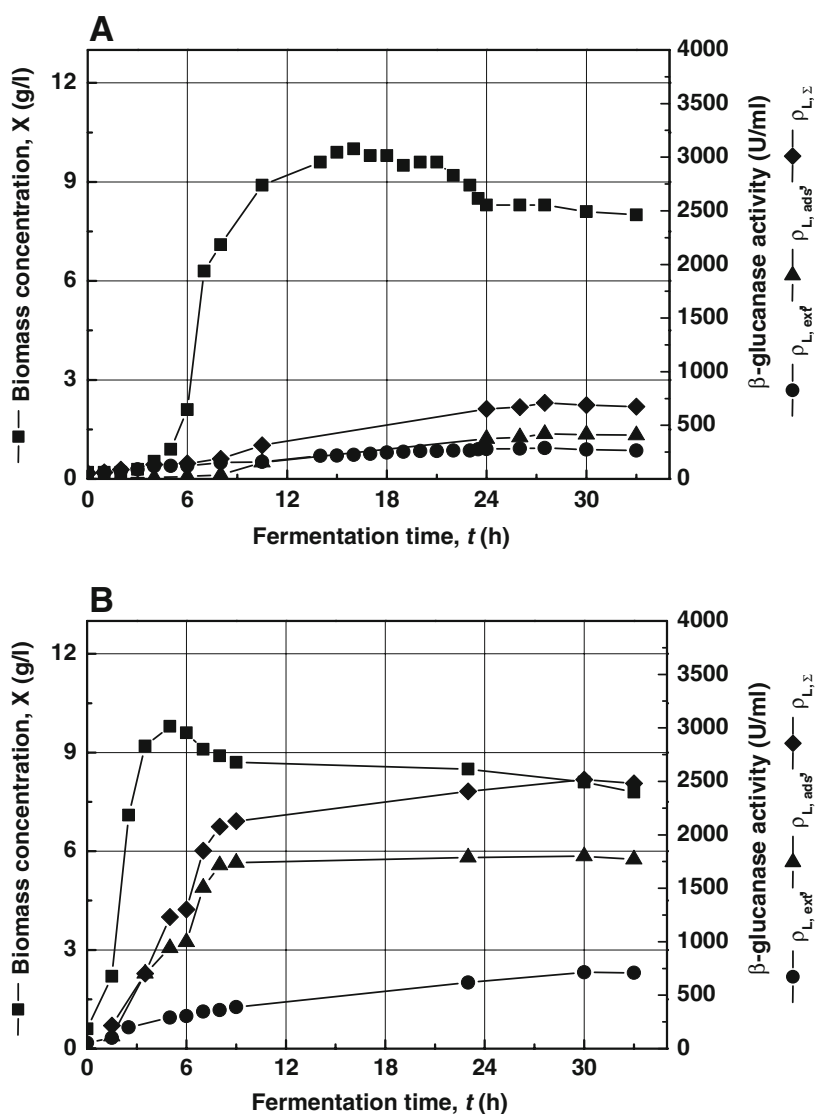

Fig. 6 Integrated process for the production of $\beta$-glucanase in the presence of uncharged (a) and $\mathrm{Zn}^{+2}$-charged (b) freely suspended PDC metal-affinity resin presented in an internal basket (Fig. 2b) in the fermenter. (E. coli BL21(DE3) pET20-bgl-his-sec; TBG medium; medium volume $500 \mathrm{ml}$, resin volume $30 \mathrm{ml}$ ) 